\title{
Strategies to Prevent Clostridium difficile Infections in Acute Care Hospitals
}

\section{Citation}

Dubberke, Erik R., Dale N. Gerding, David Classen, Kathleen M. Arias, Kelly Podgorny, Deverick J. Anderson, Helen Burstin, et al. 2008. "Strategies to Prevent Clostridium Difficile Infections in Acute Care Hospitals." Infection Control \& Hospital Epidemiology 29 (S1): S81-92. doi:10.1086/591065.

\section{Permanent link}

http://nrs.harvard.edu/urn-3:HUL.InstRepos:41543009

\section{Terms of Use}

This article was downloaded from Harvard University's DASH repository, and is made available under the terms and conditions applicable to Other Posted Material, as set forth at http:// nrs.harvard.edu/urn-3:HUL.InstRepos:dash.current.terms-of-use\#LAA

\section{Share Your Story}

The Harvard community has made this article openly available. Please share how this access benefits you. Submit a story.

Accessibility 


\section{Strategies to Prevent Clostridium difficile Infections in Acute Care Hospitals}

Erik R. Dubberke, MD; Dale N. Gerding, MD; David Classen, MD, MS; Kathleen M. Arias, MS, CIC; Kelly Podgorny, RN, MS, CPHQ; Deverick J. Anderson, MD, MPH; Helen Burstin, MD; David P. Calfee, MD, MS; Susan E. Coffin, MD, MPH; Victoria Fraser, MD; Frances A. Griffin, RRT, MPA; Peter Gross, MD; Keith S. Kaye, MD; Michael Klompas, MD; Evelyn Lo, MD; Jonas Marschall, MD; Leonard A. Mermel, DO, ScM; Lindsay Nicolle, MD;

David A. Pegues, MD; Trish M. Perl, MD; Sanjay Saint, MD; Cassandra D. Salgado, MD, MS;

Robert A. Weinstein, MD; Robert Wise, MD; Deborah S. Yokoe, MD, MPH

\section{PURPOSE}

Previously published guidelines are available that provide comprehensive recommendations for detecting and preventing healthcare-associated infections. The intent of this document is to highlight practical recommendations in a concise format designed to assist acute care hospitals in implementing and prioritizing their Clostridium difficile infection (CDI) prevention efforts. Refer to the Society for Healthcare Epidemiology of America/Infectious Diseases Society of America "Compendium of Strategies to Prevent Healthcare-Associated Infections" Executive Summary and Introduction and accompanying editorial for additional discussion.

\section{SECTION 1: RATIONALE AND STATEMENTS OF CONCERN}

1. Increasing rates of CDI

C. difficile now rivals methicillin-resistant Staphylococcus aureus (MRSA) as the most common organism to cause healthcare-associated infections in the United States. ${ }^{1}$

a. In the United States, the proportion of hospital discharges in which the patient received the International Classification of Diseases, Ninth Revision discharge diagnosis code for CDI more than doubled between 2000 and 2003, ${ }^{1}$ and CDI rates continued to increase in 2004 and 2005 (L. C. McDonald, MD, personal communication, July 2007). These increases have been seen in pediatric and adult populations, but elderly individuals have been disproportionately affected. ${ }^{1}$ CDI incidence has also increased in Canada and Europe. ${ }^{2-4}$

b. There have been numerous reports of an increase in CDI severity. ${ }^{2-6}$

c. Most reports of increases in the incidence and severity of CDI have been associated with the BI/NAP1/027 strain of C. difficile. ${ }^{2-6}$ This strain produces more toxins $\mathrm{A}$ and $\mathrm{B}$ in vitro than do many other strains of $C$. difficile, produces a third toxin (binary toxin), and is highly resistant to fluoroquinolones.

2. Outcomes associated with CDI

CDI is associated with increased lengths of hospital stay, costs, morbidity, and mortality among adult patients. Data on the changing epidemiology of CDI in pediatric patients are limited and are confounded by the prevalence of asymptomatic carriage of $C$. difficile among children younger than 12 months of age. ${ }^{7,8}$

a. CDI increases mean length of hospital stay from 2.6 days to 4.5 days. ${ }^{9,10}$

From the Washington University School of Medicine, St. Louis, Missouri (E.R.D., V.F., J.M.); the Loyola University Chicago Stritch School of Medicine (D.N.G.), the Stroger (Cook County) Hospital and the Rush University Medical Center (R.A.W.), Chicago, the Joint Commission, Oakbrook Terrace (K.P., R.W.), and the Hines Veterans Affairs Medical Center, Hines (D.N.G.), Illinois; the University of Utah, Salt Lake City (D.C.); the Association for Professionals in Infection Control and Epidemiology (K.M.A.) and the National Quality Forum (H.B.), Washington, D.C.; the Duke University Medical Center, Durham, North Carolina (D.J.A., K.S.K.); the Mount Sinai School of Medicine, New York, New York (D.P.C.); the Children's Hospital of Philadelphia and University of Pennsylvania School of Medicine, Philadelphia, Pennsylvania (S.E.C.); the Institute for Healthcare Improvement, Cambridge (F.A.G.), and the Brigham and Women's Hospital and Harvard Medical School, Boston (M.K., D.S.Y.), Massachusetts; the Hackensack University Medical Center, Hackensack (P.G.), and the University of Medicine and Dentistry-New Jersey Medical School, Newark (P.G.), New Jersey; the Warren Alpert Medical School of Brown University and Rhode Island Hospital, Providence, Rhode Island (L.A.M.); the David Geffen School of Medicine at the University of California, Los Angeles (D.A.P.); the Johns Hopkins Medical Institutions and University, Baltimore, Maryland (T.M.P.); the Ann Arbor Veterans Affairs Medical Center and the University of Michigan Medical School, Ann Arbor, Michigan (S.S.); the Medical University of South Carolina, Charleston (C.D.S.); and the University of Manitoba, Winnipeg, Canada (E.L., L.N.).

Accepted May 27, 2008; electronically published September 16, 2008.

Infect Control Hosp Epidemiol 2008; 29:S81-S92

(C) 2008 by The Society for Healthcare Epidemiology of America. All rights reserved. 0899-823X/2008/2910S1-0009\$15.00. DOI: 10.1086/591065 
b. Attributable costs of inpatient CDI have been estimated to be $\$ 2,470-\$ 3,669$ per episode. Attributable inpatient costs during the 6 months after CDI diagnosis are $\$ 5,042-\$ 7,179 .{ }^{10,11}$ US hospital costs for CDI management have been estimated to be $\$ 3.2$ billion per year. ${ }^{12}$

c. Patients with CDI were almost twice as likely to be discharged to a long-term care facility than were propensity score-matched control individuals.

d. CDI has recently been associated with an attributable mortality rate of $6.9 \%$ at 30 days after diagnosis and $16.7 \%$ at 1 year. $^{3,4,9}$

3. Changing risk factors and possible decrease in CDI treatment response rates

a. Fluoroquinolones, previously infrequently associated with CDI, have been found to be one of the primary predisposing antimicrobials in recent studies. ${ }^{3,6,13,14}$

$i$. Virtually every antibiotic has been associated with CDI. Cephalosporins, ampicillin, and clindamycin remain important predisposing antibiotics.

b. Gastric acid suppression has been recognized as a risk factor for CDI in some studies. ${ }^{14,15}$

$i$. Some studies suggest that the association between gastric acid suppression and CDI are related to other important risk factors, such as severity of illness and age. $^{14,16}$

ii. Gastric acid suppression may be an important risk factor for CDI outside of healthcare facilities. ${ }^{15}$

c. Several studies suggest that rates of response to treatment of CDI with metronidazole are declining; these studies include a randomized, prospective, blinded, and severity-stratified study that demonstrated statistically superior rates of response to vancomycin treatment for severe disease but not for mild disease, compared with metronidazole treatment. ${ }^{17-19}$

\section{SECTION 2: STRATEGIES TO DETECT CDI}

1. Surveillance definitions

Definitions for CDI surveillance in the United States and Europe have recently been published. ${ }^{20,21}$

a. In the United Kingdom, all cases of CDI in patients older than 65 years of age have been reported to the healthcare-associated infection surveillance system for National Health Service Acute Trusts in England since January $2004 .^{22}$ Reporting for all CDI cases in patients older than 2 years of age started in April 2007. ${ }^{23}$

b. The Canadian Hospital Epidemiology Committee, a joint initiative of the Canadian Infectious Diseases Society and the Canadian Nosocomial Infection Surveillance Program, used a standard definition for CDI surveillance to track nosocomial CDI over a 4-month period in 1997 and after 2005 in healthcare facilities across Canada ${ }^{24}$ (M. Miller, MD, personal communication, December 2007).

c. Data are lacking to determine the ideal definition for healthcare-associated CDI. However, this is a minor limitation in light of the need for a standardized surveillance definition for CDI. The following information focuses on the definitions for CDI surveillance in the United States and Europe..$^{20,21}$

i. A CDI case is defined as a case of diarrhea or toxic megacolon without other known etiology that meets 1 or more of the following criteria: (1) the stool sample yields a positive result of a laboratory assay for $C$. difficile toxin $\mathrm{A}$ and/or B, or a toxin-producing $C$. difficile organism is detected in the stool sample by culture or other means; (2) pseudomembranous colitis is seen on endoscopic examination or surgery; and (3) pseudomembranous colitis is seen on histopathological examination.

ii. Several CDI definitions are proposed, including community-associated CDI; community-onset, healthcare facility-associated CDI; and recurrent CDI. Healthcare facilities should track at least healthcare facilityonset, healthcare facility-associated CDI (Table 1). ${ }^{20,21}$

iii. Surveillance for CDI is limited by the use of nonculture-based methods to diagnose CDI, such as stool toxin assays, which have lower sensitivity than does $C$. difficile stool culture. ${ }^{20-22,24-27}$

2. Identifying patients with CDI

Positive results of diarrheal stool tests for toxigenic C. difficile or its toxins are the most common methods used to identify patients with CDI..$^{20-22,24}$

a. Positive results of diarrheal stool tests should automatically be sent to infection prevention and control professionals and to clinicians caring for the patient.

b. Only diarrheal stools should be tested for $C$. difficile or its toxins. A positive result of a test for toxigenic $C$. difficile and/or its toxins in a patient with diarrhea is considered to be diagnostic for CDI. However, some centers permit $C$. difficile testing of nondiarrheal stools. In such cases, review of patient records is required to ensure that the patient has symptoms consistent with CDI.

$i$. Because of the high prevalence of asymptomatic carriage of toxigenic $C$. difficile among infants younger than 1 year of age, testing should be conducted only for infants with diarrhea along with investigation of alternative causes of diarrhea. ${ }^{7,8}$ Detection of $C$. difficile toxin should not be assumed to be causative of diarrhea in these infants, although infants older than 6 months of age who are colonized have been shown to have a higher frequency of all-cause diarrhea than do noncolonized infants. ${ }^{28,29}$

c. A minority of patients have CDI diagnosed by visualization of pseudomembranes by endoscopy and/or histopathologic analysis, without positive stool test results.

3. Methods for surveillance of CDI

a. Conducting CDI surveillance to determine CDI rates provides a measure to determine the burden of $\mathrm{CDI}$ at a 
тавце 1. Clostridium difficile Infection (CDI) Surveillance Definitions

\begin{tabular}{|c|c|}
\hline CDI case type & Definition \\
\hline Healthcare facility onset, healthcare facility associated & Symptom onset $>48 \mathrm{~h}$ after admission to a healthcare facility \\
\hline Community onset, healthcare facility associated & $\begin{array}{l}\text { Symptom onset in the community or } \leqslant 48 \mathrm{~h} \text { after admis- } \\
\text { sion, provided that symptom onset was }<4 \text { weeks after the } \\
\text { last discharge from a healthcare facility }\end{array}$ \\
\hline Community associated & $\begin{array}{l}\text { Symptom onset in the community or } \leqslant 48 \mathrm{~h} \text { after admis- } \\
\text { sion to a healthcare facility, provided that symptom onset } \\
\text { was }>12 \text { weeks after the last discharge from a healthcare } \\
\text { facility }\end{array}$ \\
\hline Indeterminate onset & $\begin{array}{l}\text { Case does not fit any of the above criteria for an exposure } \\
\text { setting (eg, onset in the community }>4 \text { weeks but }<12 \\
\text { weeks after the last discharge from a healthcare facility) }\end{array}$ \\
\hline Unknown & $\begin{array}{l}\text { Exposure setting cannot be determined, because of a lack of } \\
\text { available data }\end{array}$ \\
\hline Recurrent & $\begin{array}{l}\text { Episode occurred } \leqslant 8 \text { weeks after the onset of a previous } \\
\text { episode, provided that CDI symptoms from the earlier } \\
\text { episode resolved }\end{array}$ \\
\hline
\end{tabular}

NOTE. Definitions are from McDonald et al. ${ }^{20}$ and Kuijper et al. ${ }^{21}$ When laboratory-based reporting of symptoms is used, the date and time of stool specimen collection can be used as a surrogate for symptom onset. If data on the time a patient was admitted (in addition to date) and/or the time stool was collected for testing are not available, CDI can be considered to be healthcare facility onset if stool is positive for toxigenic $C$. difficile or a C. difficile toxin after the third calendar day after hospital admission, where the first day is the day of admission (ie, a patient admitted on Monday with stool first positive for C. difficile toxin on Thursday or later is considered to have healthcare facility-onset CDI).

healthcare facility. These data are also used to assess the efficacy of interventions to prevent CDI. When they are reported back to healthcare providers and hospital administrators, CDI rates can be applied as a tool to improve adherence to CDI preventive measures.

b. Surveillance can be performed on specific wards or units and/or at the level of the entire healthcare facility.

c. Laboratories performing $C$. difficile testing should report results to infection prevention and control professionals daily. The CDI rate can be expressed as the number of CDI case patients per 10,000 patient-days.

$i$. This rate is calculated as follows: (number of case patients/number of patient-days per reporting period) $\times 10,000=$ rate per 10,000 patient-days. ${ }^{19}$

ii. To convert the rate per 10,000 patient-days to the rate per 1,000 patient-days, divide the rate by 10 (conversely, to convert a rate from 1,000 patient-days to 10,000 patient-days, multiply the rate by 10 ).

d. Because of a lack of published data on CDI surveillance using similar case-finding methods and surveillance definitions, specific definitions for what constitutes an "outbreak" or "hyperendemic" rate cannot be provided at this time.

i. An outbreak can be defined as an increase in CDI rate in time and/or space believed to be greater than that expected by chance alone.

ii. A hyperendemic rate can be defined as a persistently elevated CDI rate compared with past rates or compared with rates in other, similar healthcare facilities.

\section{SECTION 3：STRATEGIES TO PREVENT CDI}

1. Existing guidelines and recommendations

a. Published guidelines for the management of CDI are few, and only some address CDI prevention. . $2,25-27^{27}$

i. Most data published on CDI prevention are from before-after studies conducted in response to outbreaks. Often, several concomitant interventions are performed, making it difficult to determine the relative importance of one intervention compared with another. Before-after studies are also limited by time-related biases that are difficult to adjust for in the absence of a control group or properly conducted analyses, such as interrupted time series analysis. ${ }^{30,31}$ However, 2 recent studies have used these techniques, demonstrating the importance of antimicrobial stewardship and its role in preventing CDI. ${ }^{31,32}$

b. Less is known about the mechanisms and prevention of $C$. difficile transmission, compared with other antimicrobial-resistant gram-positive organisms, such as MRSA and vancomycin-resistant enterococcus (VRE). Although these 3 organisms have many common epidemiologic characteristics, C. difficile and VRE, in particular, share risk factors for transmission. ${ }^{33}$ The major difference among these 3 organisms is that $C$. difficile forms spores, whereas the other 2 do not. The formation of spores has novel (as yet unknown) implications for methods of hand hygiene and environmental disinfection, because $C$. difficile spores are resistant to the bactericidal effects of alcohol and most hospital disinfectants. 
c. General strategies to prevent CDI, per previously published guidelines, ${ }^{22,24-27}$ include the following:

$i$. Methods of reducing the risk of CDI if the organism is encountered by the patient

(a) Follow antimicrobial usage restriction and stewardship guidelines.

ii. Methods of preventing the patient from being exposed to $C$. difficile (disinfection and barrier methods)

(a) Avoid the use of electronic thermometers; the handles become contaminated with $C$. difficile.

(b) Use dedicated patient care items and equipment; if items must be shared, clean and disinfect the equipment between patients.

(c) Use full barrier precautions (gowns and gloves) for contact with patients with CDI and for contact with their body substances and environment (contact precautions).

(d) Place patients with CDI in private rooms, if available; give isolation preference to patients with fecal incontinence if room availability is limited.

(e) Perform meticulous hand hygiene based on Centers for Disease Control and Prevention or World Health Organization guidelines before and after entering the room of a patient with CDI, with soap and water or an alcohol-based hand-hygiene product (in routine settings or settings of endemicity). Perform hand hygiene with soap and water preferentially, instead of alcohol hand hygiene products, after caring for a patient with CDI in outbreak settings or settings of hyperendemicity. Ensure that proper hand-hygiene techniques are used when hand washing with soap and water is employed. ${ }^{34}$

(f) Perform environmental decontamination of rooms housing patients with $\mathrm{CDI}$, using sodium hypochlorite (household bleach) diluted $1: 10$ with water, in an outbreak setting or setting of hyperendemicity.

(g) Educate healthcare personnel and hospital administration about the clinical features, transmission, and epidemiology of CDI.

d. Other important principles to be aware of when caring for patients with CDI include the following: ${ }^{22,25-27}$

$i$. Perform testing for $C$. difficile only on unformed diarrheal stools (toxin testing of formed stool is strongly discouraged).

ii. Do not give prophylactic antimicrobial CDI therapy (eg, with metronidazole or vancomycin) to patients at high risk for CDI.

iii. Do not treat or attempt to decolonize asymptomatic $C$. difficile carriers. Antimicrobial therapy is not effective for decolonization.

$i v$. Do not conduct repeated testing for $C$. difficile if a patient has had a stool sample positive for $C$. difficile, unless symptoms resolved with treatment and then re- turned after treatment (ie, do not perform test of cure in patients successfully treated for CDI).

\section{Infrastructure requirements}

a. Trained infection prevention and control personnel

$i$. Infection prevention and control personnel must have knowledge about risk factors for and methods to prevent CDI. They must also be trained in how to determine when a case of CDI is healthcare associated and how to calculate CDI rates. ${ }^{20,21}$

b. Method to identify patients with CDI

$i$. Infection prevention and control personnel must be able to identify patients with CDI as soon as possible after their condition is diagnosed. This is necessary to ensure that patients are placed under contact precautions in a timely fashion. These data can also be used to calculate CDI rates.

c. Ability to place patients with CDI under contact precautions

$i$. Contact precautions require the ability to place patients in a private room (preferably) or to cohort patients with CDI, as well as to place materials necessary for compliance with contact precautions (eg, gowns and gloves) in an easily accessible space outside of the patient's room.

ii. Place a sign indicating that the patient is under contact precautions outside of the patient's room.

iii. If there is a limited number of single-bed rooms, patients with stool incontinence should preferentially be placed in these rooms.

$i v$. If it is necessary to cohort patients, cohort patients who are colonized or infected with the same organism(s) (eg, do not cohort patients with CDI who are discordant in their VRE or MRSA colonization status).

$v$. Have systems in place to facilitate communication among infection prevention and control, admitting, nursing, and housekeeping departments and develop contingency plans for conditions of limited bed availability.

d. Provide educational materials for patients, family members, and healthcare personnel that include explanations of CDI, why contact precautions are necessary, and the importance of hand hygiene.

e. Provide adequate resources and training for housekeeping personnel to ensure proper cleaning of rooms.

\section{Initiating a CDI prevention program}

a. Pilot test the intervention in 1 patient care location to assess efficacy.

$i$. Perform CDI surveillance to determine locations where CDI rates are highest.

ii. Initiate the prevention program where there is a high concentration of patients at risk for CDI, such as an intensive care unit or an oncology ward.

iii. Start in 1 patient care location. 
(a) Identify opportunities to improve the system for identifying patients with CDI.

(b) Identify opportunities to improve the process for placing patients with CDI under contact precautions and to minimize problems for family members, visitors, and healthcare personnel.

iv. Obtain the support of hospital administration and local physician and nursing leadership before starting the program.

b. Use process and outcome measures to determine whether the intervention is effective.

c. Replicate the CDI infection prevention and control program in other patient care areas when it is determined that the systems developed are effective.

\section{SECTION 4: RECOMMENDATIONS FOR IMPLEMENTING PREVENTION AND \\ MONITORING STRATEGIES}

Recommendations for preventing and monitoring CDI are summarized in the following section. They are designed to assist acute care hospitals in prioritizing and implementing their CDI prevention efforts. Criteria for grading the strength of recommendation and quality of evidence are described in Table 2.

\section{Basic practices for prevention and monitoring of CDI: recommended for all acute care hospitals}

\section{A. Components of a CDI prevention program}

1. Use contact precautions for infected patients, with a single-patient room preferred (A-II for hand hygiene, A-I for gloves, B-III for gowns, and B-III for single-patient room). ${ }^{22,25-27}$

a. Place patients with CDI under contact precautions to help reduce patient-to-patient spread of the organism.

$i$. Place patients in private rooms when available. ii. Don gown and gloves on entry to the patient's room.

(a) Gloves should be changed immediately if visibly soiled and after touching or handling surfaces or materials contaminated with feces.

iii. Remove gown and gloves before exiting the room. iv. Conduct Centers for Disease Control and Prevention- or World Health Organization-compliant hand hygiene on exiting the patient's room.

$v$. Cohorting patients with CDI is acceptable when single, private rooms are not available.

(a) Place patients with stool incontinence preferentially in private rooms.

(b) Do not cohort patients who have discordant status of infection or colonization with other epidemiologically important organisms (eg, VRE and MRSA).

(c) Remove gowns and gloves and perform hand hygiene when moving from one patient to another.

b. Ensure that adequate supplies for contact precautions are readily available.

i. Management leaders are responsible to ensure that necessary barrier-equipment supplies (eg, gowns and gloves) and hand-hygiene products are readily available.

ii. Assign responsibility for monitoring the availability and restocking of supplies to specific healthcare personnel.

c. Criteria for discontinuing contact precautions

i. The Centers for Disease Control and Prevention currently recommends contact precautions for the duration of illness when caring for patients with CDI. ${ }^{36}$ Some experts recommend continuing contact precautions for at least 48 hours after diarrhea resolves. Areas of controversy include the following:

(a) Asymptomatically colonized patients (including, in many cases, those successfully treated for CDI)

TABLE 2. Strength of Recommendation and Quality of Evidence

\begin{tabular}{ll}
\hline Category/grade & \multicolumn{1}{c}{ Definition } \\
\hline $\begin{array}{l}\text { Strength of recommendation } \\
\text { A }\end{array}$ & Good evidence to support a recommendation for use \\
B & Moderate evidence to support a recommendation for use \\
C & Poor evidence to support a recommendation \\
Quality of evidence & Evidence from $\geqslant 1$ properly randomized, controlled trial \\
I & Evidence from $\geqslant 1$ well-designed clinical trial, without \\
II & randomization; from cohort or case-control analytic \\
& studies (preferably from $>1$ center); from multiple \\
& time series; or from dramatic results from uncontrolled \\
& experiments \\
III & Evidence from opinions of respected authorities, based \\
& on clinical experience, descriptive studies, or reports of \\
& expert committees \\
\hline
\end{tabular}

nоте. Adapted from the Canadian Task Force on the Periodic Health Examination. ${ }^{35}$ 
continue to shed $C$. difficile spores, but the number of spores and degree of contamination is not as great as for patients with active CDI. There are currently no data to support isolation of these asymptomatic patients. ${ }^{37-39}$

(b) Prolonging the duration of contact isolation for patients with CDI is recommended when CDI is not effectively controlled by the use of basic practices (see below: II. Special Approaches for the Prevention of CDI). Similarly, there are no data to indicate the efficacy of this practice at this time.

2. Ensure cleaning and disinfection of equipment and the environment (B-III for equipment and B-II for the environment).

a. C. difficile spores contaminate the environment in which patients are housed and the equipment used to care for them..$^{26,27,37-39}$ This includes the following:

$i$. Furnishings in the room, including over-bed tables, bed rails, furniture, sinks, floors, commodes, and toilets

ii. Patient care equipment that directly touches patients, such as thermometers, stethoscopes, and blood pressure cuffs

iii. "High-touch" (ie, frequently touched) surfaces, such as door knobs and intravenous fluid pumps

b. C. difficile appears to contaminate very few surfaces outside patient rooms. ${ }^{37}$

c. Contaminated surfaces and equipment are potential reservoirs for transmission of $C$. difficile.

$i$. Recent guidelines have outlined environmental disinfection protocols. ${ }^{40}$ There are no US Environmental Protection Agency-registered products specific for inactivating $C$. difficile spores. Data are conflicting as to whether inactivation of spores is necessary to prevent C. difficile transmission, especially in a setting of endemicity.

ii. Facilities should consider using a $1: 10$ dilution of sodium hypochlorite (household bleach) for environmental disinfection in outbreak settings and settings of hyperendemicity in conjunction with other infection prevention and control measures (see below: II. Special Approaches for the Prevention of CDI). The bleach solution should have a contact time of at least 10 minutes. ${ }^{41}$

d. Develop and implement protocols for disinfection of equipment and the environment.

i. On a routine basis, assess adherence to protocols and the adequacy of cleaning.

ii. Assess the adequacy of cleaning before changing to a new cleaning product (eg, bleach). If cleaning is not adequate, address this before changing products (see below: II. Special Approaches for the Prevention of CDI).

iii. Because of the high turnover of housekeeping personnel, educate personnel on proper cleaning technique frequently. Ensure that education is provided in the personnel's native language. e. Dedicate noncritical patient care items, such as blood pressure cuffs, stethoscopes, and thermometers, to a single patient with CDI.

$i$. When this is not possible, ensure adequate cleaning and disinfection of shared items between patient encounters. Ensure that the manufacturers' recommendations for contact time of disinfectants are followed.

3. Implement a laboratory-based alert system to provide immediate notification to infection prevention and control personnel and clinical personnel about patients with newly diagnosed CDI (B-III).

a. To place patients with CDI under contact precautions in a timely manner, it is important that an alert system be developed between the laboratory and both infection prevention and control personnel and clinical personnel caring for the patient. This alert system should immediately notify infection prevention and control and clinical personnel when a patient has newly diagnosed CDI.

b. There are a variety of methods by which this information can be transmitted, but some options include fax alerts, phone call and pager alerts, or automated secure electronic alerts.

$i$. The alert system should not rely on fax transmissions alone, because there may be delays from the time the transmission is received to the time it is seen by an appropriate healthcare provider.

c. Alert patient care areas of positive test results immediately, so that these patients can be placed under contact precautions.

d. When a patient has active CDI, communicate the CDI status when transferring the patient to another healthcare facility, so that appropriate precautions can be implemented at the accepting facility.

4. Conduct CDI surveillance and analyze and report CDI data (B-III).

a. At a minimum, calculate healthcare facility-onset, healthcare facility-associated CDI rates at the unit/ward and organizational levels (Table 1). ${ }^{20,21}$

b. Provide CDI data and other CDI prevention process and outcome measures to key stakeholders, including senior leadership, physicians, nursing staff, and other clinicians.

c. Provide the process and outcome measures outlined in the "Performance Measures" section below to appropriate hospital staff and administrators on a regular basis. The frequency with which these data are provided will depend on the hospital's existing reporting structure and the type of data collected. These data can be added to routine quality assessment and performance improvement reports.

5. Educate healthcare personnel, housekeeping personnel, and hospital administration about CDI (B-III). 
a. Include risk factors, routes of transmission, local CDI epidemiology, patient outcomes and treatment, and prevention measures (including Centers for Disease Control and Prevention and World Health Organization recommendations regarding proper hand hygiene, contact precautions, and management of multidrug-resistant organisms)..$^{34,42,43}$

6. Educate patients and their families about CDI, as appropriate (B-III).

a. Although often not considered part of a program to reduce transmission of multidrug-resistant organisms, proper education may help to alleviate patient fears regarding being placed in isolation. ${ }^{44}$

$i$. Include information about anticipated questions: general information about CDI, colonization versus infection, the hospital's CDI prevention program, the components of and rationale for contact precautions, and the risk of transmission to family and visitors while in the hospital and after discharge. Helpful materials might include patient education sheets in appropriate language(s) and the use of patient education channels, Web sites, or VHS tapes and DVDs.

7. Measure compliance with Centers for Disease Control and Prevention or World Health Organization hand-hygiene and contact precaution recommendations (B-III).

a. Patient-to-patient transmission of $C$. difficile is thought to occur primarily through transient contamination of the hands of healthcare personnel with spores.

b. Glove use when caring for patients with CDI or touching surfaces in their rooms has been shown to be effective at preventing the transmission of $C$. difficile.

c. Hand-hygiene practices in compliance with Centers for Disease Control and Prevention or World Health Organization guidelines are critical to $C$. difficile control and prevention. Evidence-based recommendations for implementation and assessment of hand-hygiene programs in healthcare settings have been published. ${ }^{34}$

$i$. Area of controversy: There are concerns regarding reliance on alcohol-based hand-hygiene products, because alcohol is not sporicidal. Conversely, hand washing with soap and water is associated with much lower compliance. In settings where CDI is endemic, it appears the potential decrease in efficacy of alcohol-based hand-hygiene products for removing spores, compared with hand washing, may be offset by the increase in handhygiene adherence with alcohol-based hand-hygiene products, if contact precautions are followed (ie, if gloves and gowns are worn) when caring for patients with CDI. ${ }^{45}$

\section{B. Accountability}

1. The hospital's chief executive officer and senior man- agement are responsible for ensuring that the healthcare system supports an infection prevention and control program that effectively prevents CDI and the transmission of epidemiologically significant pathogens.

2. Senior management is accountable for ensuring that an adequate number of trained personnel are assigned to the infection prevention and control program.

3. Senior management is accountable for ensuring that healthcare personnel, including licensed and nonlicensed personnel, are competent to perform their job responsibilities.

4. Direct healthcare providers (such as physicians, nurses, aides, and therapists) and ancillary personnel (such as housekeeping and equipment-processing personnel) are responsible for ensuring that appropriate infection prevention and control practices are used at all times (including hand hygiene, standard and isolation precautions, and cleaning and disinfection of equipment and the environment).

5. Hospital and unit leaders are responsible for holding personnel accountable for their actions.

6. The person who manages the infection prevention and control program is responsible for ensuring that an active program to identify CDI is implemented, that data on CDI are analyzed and regularly provided to those who can use the information to improve the quality of care (eg, unit staff, clinicians, and hospital administrators), and that evidencebased practices are incorporated into the program.

7. Personnel responsible for healthcare personnel and patient education are accountable for ensuring that appropriate training and educational programs to prevent CDI are developed and provided to personnel, patients, and families.

8. Personnel from the infection prevention and control program, the laboratory, and information technology departments are responsible for ensuring that systems are in place to support the surveillance program.

\section{Special approaches for the prevention of CDI}

Perform a CDI risk assessment. These special approaches are recommended for use in locations and/or populations within the hospital that have unacceptably high CDI rates despite implementation of the basic CDI prevention strategies listed above.

There are several unresolved issues regarding CDI prevention. This is apparent when reviewing the rankings of each recommendation on the basis of the quality of the data to support it. As a result, implementation of the recommendations beyond the basic practices to prevent CDI should be individualized at each healthcare facility. One may consider a "tiered" approach in which recommendations are instituted 
individually or in groups; additional "tiers" are added if CDI rates do not improve, with implementation of basic practices as the first tier.

A. Approaches to minimize $C$. difficile transmission by healthcare personnel

1. Intensify the assessment of compliance with process measures (B-III).

a. Contact precautions: Gowns and gloves should be worn by all healthcare personnel who enter the rooms of patients under contact precautions.

b. Hand hygiene: Hand hygiene should be performed on entry and exit from patient rooms. When hand washing is performed, determine whether proper techniques are being used (eg, hand washing for at least 15 seconds). ${ }^{34}$

c. If hand-hygiene compliance or techniques are not adequate, conduct interventions to improve hand-hygiene compliance and techniques.

2. Perform hand hygiene with soap and water as the preferred method before exiting the room of a patient with CDI (B-III).

a. Ensure proper hand-hygiene technique when using soap and water. ${ }^{34}$

b. Be aware that hand-hygiene adherence may decrease when soap and water is the preferred method.

$i$. Additional education may be necessary to remind healthcare workers that alcohol-based hand-hygiene products are superior to hand washing for non-sporeforming organisms (eg, MRSA).

3. Place patients with diarrhea under contact precautions while $C$. difficile test results are pending (B-III).

a. To decrease transmission, it is essential to place symptomatic patients under contact precautions as soon as diarrhea symptoms are recognized.

b. If the results of $C$. difficile testing are negative, the patient has a low pretest probability of CDI, and the patient is continent of stool, contact precautions can be discontinued.

$i$. Because of concerns about the low sensitivity of enzyme immunoassays, clinical suspicion of CDI should outweigh negative test results for patients with a high pretest probability of having CDI.

4. Prolong the duration of contact precautions after the patient becomes asymptomatic until hospital discharge (BIII).

a. Patients may still shed $C$. difficile in their stool after diarrhea resolves. ${ }^{46-48}$

B. Approaches to minimize CDI transmission from the environment

1. Assess the adequacy of room cleaning (B-III). a. If room cleaning practices are deemed to be inadequate, focus on improving room cleaning techniques.

b. Important issues to address include proper dilution of cleaning products, adequacy of cleaning technique, cleaning "high-touch" surfaces, frequency of changing rags/ mop water, and moving from "clean" areas to "dirty" areas.

$i$. Create a checklist based on cleaning protocols and perform observations to monitor cleaning practice.

ii. Environmental culture for $C$. difficile is difficult to perform and requires specialized media; therefore, it is not routinely recommended. ${ }^{49}$

c. Consider environmental decontamination with sodium hypochlorite if room cleaning is deemed to be adequate but there is ongoing CDI transmission (see below).

2. Use sodium hypochlorite (bleach)-containing cleaning agents for environmental cleaning. Implement a system to coordinate with the housekeeping department if it is determined that sodium hypochlorite is needed for environmental disinfection (B-II).

a. Area of controversy: Data on the ability of diluted sodium hypochlorite or other sporicidal agents used for environmental decontamination to control CDI have not been consistent. However, a beneficial effect has been reported when bleach has been used in outbreak settings or settings of hyperendemicity, typically in conjunction with other enhanced CDI control measures. ${ }^{40,50-53}$

b. When diluted sodium hypochlorite is instituted for environmental decontamination, it is necessary to coordinate activities with housekeeping staff.

i. Clinical, infection prevention and control, and housekeeping staff will need to determine the location, type, and frequency of diluted sodium hypochlorite use. For instance:

(a) All rooms, only rooms of patients with CDI, or outside of patient rooms?

(b) Daily cleaning or terminal cleaning only when the patient is discharged or transferred?

c. When diluted sodium hypochlorite is used, it is important to address the following issues:

i. Avoid toxicity to patients and staff and damage to equipment and the environment from bleach use. Sodium hypochlorite can be corrosive and irritating to patients, housekeeping staff, and other healthcare personnel.

ii. The sodium hypochlorite solution must be mixed fresh daily.

d. When sodium hypochlorite will be used only in the rooms of patients with CDI, a system will need to be created to identify these patients to the housekeeping staff.

C. Approaches to reduce the risk of CDI acquisition

1. Initiate an antimicrobial stewardship program (AII). ${ }^{22,25-27,32,54,55}$ 
a. Assess the appropriateness of antimicrobial prescribing practices.

$i$. Restrict antimicrobials that are strongly associated with CDI and promote appropriate antimicrobial use.

\section{Approaches that should not be considered a routine part of CDI prevention}

1. Do not test patients without signs or symptoms of CDI for C. difficile (B-II).

a. C. difficile toxin tests have been studied in patients with symptoms of CDI and a high pretest probability of having CDI. A positive $C$. difficile toxin test result for a patient without symptoms has a high probability of being a false-positive result.

i. Only stool culture for $C$. difficile has been confirmed to identify patients with asymptomatic $C$. difficile colonization. The sensitivity, specificity, and negative and positive prediction values of antigen and toxin assays are unknown for asymptomatic patients.

b. Obtaining stool specimens requires nursing time to collect and laboratory technician time to perform the test and report results.

c. A positive toxin test result for an asymptomatic patient may result in the initiation of unnecessary treatment for CDI, which may increase the patient's risk of developing CDI in the future. ${ }^{56}$

d. Do not place patients with asymptomatic $C$. difficile colonization under contact precautions.

$i$. Area of controversy: Previous research has demonstrated that asymptomatically colonized patients can be a source of transmission of $C$. difficile and that patients can remain colonized after symptoms cease. ${ }^{38,39,47-49}$ However, asymptomatically colonized patients are less likely than symptomatic patients to contaminate their surrounding environment or serve as a source of transmission. In some settings, the duration of contact precautions can be extended if there is concern that asymptomatically colonized patients represent a significant source of potential $C$. difficile exposure.

e. Do not attempt to decolonize asymptomatic patients, because this has not been effective and may increase the patient's risk of developing CDI in the future. ${ }^{56}$

2. Do not repeat $C$. difficile testing at the end of successful therapy for a patient recently treated for CDI (B-III).

a. A positive test result may result in unnecessary prolongation of contact precautions and CDI treatment.

$i$. In some settings, contact precautions may be extended until hospital discharge after symptom resolution (see above). However, there are insufficient data to recommend extending the duration of contact precautions on the basis of whether $C$. difficile or its toxins can be detected in the patient's stool. b. A positive test result at the end of therapy does not predict who will develop a recurrence or relapse. ${ }^{48}$

c. Repeated $C$. difficile testing does not provide any useful clinical information but requires nursing time to collect the specimen and laboratory technician time to perform the test and report results. ${ }^{48}$

\section{Unresolved issues}

1. Use of gowns and gloves by family members and other visitors

a. The utility of requiring family members and other visitors to wear gowns and gloves to prevent $C$. difficile transmission is unknown. ${ }^{57}$ The risk that family members and other visitors will transmit $C$. difficile between patients is likely to be related to the degree of contact the visitor has with the patient and the patient's environment, whether the visitor performs hand hygiene, and the degree of interaction the visitor has with other patients. At a minimum, family members and other visitors should be instructed to perform hand hygiene whenever entering or leaving the patient's room.

2. Standing orders or nurse-driven protocols to test all patients with diarrhea for $C$. difficile

a. Nurses frequently know, before the treating physician does, when a patient has diarrhea

3. Admitting-based alert systems that notify infection prevention and control and clinical personnel about readmitted or transferred patients with a history of CDI

a. This information can be integrated into a computerized database used during admission and registration or a separate electronic or paper-based database.

$i$. If an alert system is implemented, patients with a history of CDI should be placed under contact precautions if they are readmitted only if they have symptoms consistent with CDI at admission. Asymptomatic patients with a history of CDI do not require contact precautions.

ii. The duration that the alert should remain active is unknown. Nearly all cases of recurrent CDI occur within 90 days after the last episode. On the basis of this fact, it is reasonable to discontinue the alert 90 days after the last episode of CDI. However, healthcare facilities may not be aware of recurrent episodes of CDI that are diagnosed and managed in outpatient settings, so an arbitrary cutoff based on the last known episode of CDI may inadvertently remove patients with ongoing recurrent CDI.

4. Ongoing assessment of CDI knowledge and intensified CDI education among healthcare personnel

a. Re-educate staff if prior CDI training occurred more 
than 12 months earlier or if overall knowledge is deemed to be inadequate.

$i$. Include housekeeping personnel in educational efforts.

5. Restricting the use of gastric acid suppressants ${ }^{14,16}$

\section{SECTION 5：PERFORMANCE MEASURES}

\section{Internal reporting}

These performance measures are intended to support internal hospital quality improvement efforts and do not necessarily address external reporting needs. The process and outcome measures suggested here are derived from published guidelines, other relevant literature, and the opinions of the authors. Report process and outcome measures to senior hospital leadership, nursing leadership, and clinicians who care for patients at risk for CDI.

\section{A. Process measures}

1. Compliance with hand-hygiene guidelines

a. Preferred measure for hand-hygiene compliance

i. Numerator: number of observed proper hand-hygiene episodes performed by healthcare personnel.

ii. Denominator: total number of observed opportunities for hand hygiene.

iii. Multiply by 100 so that the measure is expressed as a percentage.

b. If hand hygiene with soap and water is the preferred method of hand hygiene when caring for patients with CDI, also assess proper hand washing techniques (minimum duration of 15 seconds).

$i$. Numerator: number of proper hand washing episodes with proper technique.

ii. Denominator: total number of hand washing episodes observed.

iii. Multiply by 100 so that the measure is expressed as a percentage.

2. Compliance with contact precautions

a. Preferred measure of contact precautions compliance $i$. Numerator: number of observed patient care episodes in which contact precautions are appropriately implemented.

ii. Denominator: number of observed patient care episodes in which contact precautions are indicated.

iii. Multiply by 100 so that the measure is expressed as a percentage.

3. Compliance with environmental cleaning

a. One specific measure of compliance for use in all hospitals cannot be recommended. However, many hos- pitals use checklists and environmental rounds to assess the cleaning process and cleanliness of equipment and the environment (see above).

B. Outcome measures

Perform ongoing measurement of the incidence density of CDI to permit longitudinal assessment of the processes of care.

1. CDI rates should be calculated according to the recently published recommendations and as described above..$^{20,22}$

a. See Table 1 for case definitions.

i. Numerator: number of CDI cases in the population being monitored (the specific cases included in the numerator depends on the definition used; see Table 1).

ii. Denominator: total number of patient-days in the population being monitored.

iii. Multiply by 10,000 so that measure is expressed as number of cases per 10,000 patient-days.

b. To convert the rate per 10,000 patient-days to 1,000 patient-days, divide the rate by 10 (conversely, to convert a rate from 1,000 patient-days to 10,000 patient-days, multiply the rate by 10 ).

\section{External reporting}

There are many challenges in providing useful information to consumers and other stakeholders while preventing unintended adverse consequences of public reporting of healthcare-associated infections. ${ }^{58}$ Recommendations for public reporting of healthcare-associated infections have been provided by the Hospital Infection Control Practices Advisory Committee, ${ }^{59}$ the Healthcare-Associated Infection Working Group of the Joint Public Policy Committee, ${ }^{60}$ and the National Quality Forum. ${ }^{61}$

Given the absence until recently of standardized CDI surveillance definitions and the difficulties in ascertaining the specific time and location of $C$. difficile acquisition, specific recommendations for external reporting of CDI rates cannot be made at this time.

\section{A. State and local requirements}

1. Hospitals in states that have mandatory reporting requirements for CDI must collect and report the data required by the state.

2. For information on local requirements, check with your state or local health department.

\section{B. External quality initiatives}

1. Hospitals that participate in external quality initiatives must collect and report the data if required by the initiative. 


\section{ACKNOWLEDGMENTS}

For Potential Conflicts of Interest statements and information on financial support, please see the Acknowledgments in the Executive Summary, on page S20 of this supplement.

Address reprint requests to the Reprints Coordinator, University of Chicago Press, 1427 E. 60th St., Chicago, IL 60637 (reprints@press.uchicago.edu) or contact the journal office (iche@press.uchicago.edu).

\section{REFERENCES}

1. McDonald LC, Owings M, Jernigan DB. Clostridium difficile infection in patients discharged from US short-stay hospitals, 1996-2003. Emerg Infect Dis 2006; 12:409-415.

2. Kuijper EJ, Coignard B, Tull P. Emergence of Clostridium difficile-associated disease in North America and Europe. Clin Microbiol Infect 2006; 12(Suppl 6):2-18.

3. Loo VG, Poirier L, Miller MA, et al. A predominantly clonal multiinstitutional outbreak of Clostridium difficile-associated diarrhea with high morbidity and mortality. N Engl J Med 2005; 353:2442-2449.

4. Pepin J, Valiquette L, Cossette B. Mortality attributable to nosocomial Clostridium difficile-associated disease during an epidemic caused by a hypervirulent strain in Quebec. CMAJ 2005; 173:1037-1042.

5. McDonald LC, Killgore GE, Thompson A, et al. An epidemic, toxin gene-variant strain of Clostridium difficile. N Engl J Med 2005; 353:24332441.

6. Muto CA, Pokrywka M, Shutt K, et al. A large outbreak of Clostridium difficile-associated disease with an unexpected proportion of deaths and colectomies at a teaching hospital following increased fluoroquinolone use. Infect Control Hosp Epidemiol 2005; 26:273-280.

7. Jarvis WR, Feldman RA. Clostridium difficile and gastroenteritis: how strong is the association in children? Pediatr Infect Dis 1984; 3:4-6.

8. Welch DF, Marks MI. Is Clostridium difficile pathogenic in infants? J Pediatr 1982; 100:393-395.

9. Dubberke ER, Reske KA, Butler AM, et al. Attributable outcomes of Clostridium difficile-associated disease in non-surgical patients. Emerg Infect Dis (in press).

10. Kyne L, Hamel MB, Polavaram R, Kelly CP. Health care costs and mortality associated with nosocomial diarrhea due to Clostridium difficile. Clin Infect Dis 2002; 34:346-353.

11. Dubberke ER, Reske KA, Olsen MA, McDonald LC, Fraser VJ. Short and long term attributable cost of Clostridium difficile-associated disease in non-surgical patients. Clin Infect Dis 2008; 46:497-504.

12. O’Brien JA, Lahue BJ, Caro JJ, Davidson DM. The emerging infectious challenge of Clostridium difficile-associated disease in Massachusetts hospitals: clinical and economic consequences. Infect Control Hosp Epidemiol 2007; 28:1219-1227.

13. Dubberke ER, Reske KA, Yan Y, Olsen MA, McDonald LC, Fraser VJ. Clostridium difficile-associated disease in a setting of endemicity: identification of novel risk factors. Clin Infect Dis 2007; 45:1543-1549.

14. Pepin J, Saheb N, Coulombe MA, et al. Emergence of fluoroquinolones as the predominant risk factor for Clostridium difficile-associated diarrhea: a cohort study during an epidemic in Quebec. Clin Infect Dis 2005; 41:1254-1260.

15. Dial S, Delaney JA, Barkun AN, Suissa S. Use of gastric acid-suppressive agents and the risk of community-acquired Clostridium difficile-associated disease. JAMA 2005; 294:2989-2995.

16. Beaulieu M, Williamson D, Pichette G, Lachaine J. Risk of Clostridium difficile-associated disease among patients receiving proton-pump inhibitors in a Quebec medical intensive care unit. Infect Control Hosp Epidemiol 2007; 28:1305-1307.

17. Musher DM, Aslam S, Logan N, et al. Relatively poor outcome after treatment of Clostridium difficile colitis with metronidazole. Clin Infect Dis 2005; 40:1586-1590.
18. Pepin J, Alary ME, Valiquette L, et al. Increasing risk of relapse after treatment of Clostridium difficile colitis in Quebec, Canada. Clin Infect Dis 2005; 40:1591-1597.

19. Zar FA, Bakkanagari SR, Moorthi KM, Davis MB. A comparison of vancomycin and metronidazole for the treatment of Clostridium difficileassociated diarrhea, stratified by disease severity. Clin Infect Dis 2007; 45:302-307.

20. McDonald LC, Coignard B, Dubberke E, Song X, Horan T, Kutty PK. Recommendations for surveillance of Clostridium difficile-associated disease. Infect Control Hosp Epidemiol 2007; 28:140-145.

21. Kuijper EJ, Coignard B, Tull P, ESCMID Study Group for Clostridium difficile; EU Member States; European Centre for Disease Prevention and Control. Emergence of Clostridium difficile-associated disease in North America and Europe. Clin Microbiol Infect 2006; (Suppl 6):2-18.

22. National Clostridium difficile Standards Group. National Clostridium difficile Standards Group: report to the Department of Health. J Hosp Infect 2004; 56(Suppl 1):1-38.

23. United Kingdom Department of Health. Changes to the mandatory healthcare associated infection surveillance system for Clostridium difficile associated diarrhea from April 2007. Available at: http://www.dh.gov.uk/ en/Publicationsandstatistics/Lettersandcirculars/Professionalletters/ Chiefmedicalofficerletters/DH_073767. Accessed November 28, 2007.

24. Miller MA, Hyland M, Ofner-Agostini M, Gourdeau M, Ishak M. Morbidity, mortality, and healthcare burden of nosocomial Clostridium difficile-associated diarrhea in Canadian hospitals. Infect Control Hosp Epidemiol 2002; 23:137-140.

25. Fekety R. Guidelines for the diagnosis and management of Clostridium difficile-associated diarrhea and colitis. American College of Gastroenterology, Practice Parameters Committee. Am J Gastroenterol 1997; 92: 739-750.

26. Gerding DN, Johnson S, Peterson LR, Mulligan ME, Silva J Jr. Clostridium difficile-associated diarrhea and colitis. Infect Control Hosp Epidemiol $1995 ; 16: 459-477$.

27. Simor AE, Bradley SF, Strausbaugh LJ, Crossley K, Nicolle LE. Clostridium difficile in long-term-care facilities for the elderly. Infect Control Hosp Epidemiol 2002; 23:696-703.

28. Tullus K, Aronsson B, Marcus S, Mollby R. Intestinal colonization with Clostridium difficile in infants up to 18 months of age. Eur J Clin Microbiol Infect Dis 1989; 8:390-393.

29. Merida V, Moerman J, Colaert J, Lemmens P, Vandepitte J. Significance of Clostridium difficile and its cytotoxin in children. Eur J Pediatr 1986; 144:494-496.

30. Harris AD, Bradham DD, Baumgarten M, Zuckerman IH, Fink JC, Perencevich EN. The use and interpretation of quasi-experimental studies in infectious diseases. Clin Infect Dis 2004; 38:1586-1591.

31. Stone SP, Cooper BS, Kibbler CC, et al. The ORION statement: guidelines for transparent reporting of outbreak reports and intervention studies of nosocomial infection. J Antimicrob Chemother 2007; 59:833-840.

32. Fowler S, Webber A, Cooper BS, et al. Successful use of feedback to improve antibiotic prescribing and reduce Clostridium difficile infection: a controlled interrupted time series. J Antimicrob Chemother 2007; 59: 990-995.

33. Shadel BN, Puzniak LA, Gillespie KN, Lawrence SJ, Kollef M, Mundy LM. Surveillance for vancomycin-resistant enterococci: type, rates, costs, and implications. Infect Control Hosp Epidemiol 2006; 27:1068-1075.

34. Boyce JM, Pittet D. Guideline for hand hygiene in health-care settings: recommendations of the Healthcare Infection Control Practices Advisory Committee and the HICPAC/SHEA/APIC/IDSA Hand Hygiene Task Force. Society for Healthcare Epidemiology of America/Association for Professionals in Infection Control/Infectious Diseases Society of America. MMWR Recomm Rep 2002; 51:1-45, quiz.

35. Canadian Task Force on the Periodic Health Examination. The periodic health examination. Can Med Assoc J 1979; 121:1193-1254.

36. Centers for Disease Control and Prevention. C. difficile frequently asked questions information for healthcare providers. 2005. Available at: http: 
//www.cdc.gov/ncidod/dhqp/id_CdiffFAQ_HCP.html. Accessed August 18, 2007.

37. Dubberke ER, Reske KA, Noble-Wang J, et al. Prevalence of Clostridium difficile environmental contamination and strain variability in multiple health care facilities. Am J Infect Control 2007; 35:315-318.

38. Johnson S, Clabots CR, Linn FV, Olson MM, Peterson LR, Gerding DN. Nosocomial Clostridium difficile colonisation and disease. Lancet 1990; 336:97-100.

39. McFarland LV, Mulligan ME, Kwok RY, Stamm WE. Nosocomial acquisition of Clostridium difficile infection. N Engl J Med 1989; 320:204210.

40. Sehulster L, Chinn RY. Guidelines for environmental infection control in health-care facilities. Recommendations of CDC and the Healthcare Infection Control Practices Advisory Committee (HICPAC). MMWR Recomm Rep 2003; 52:1-42.

41. Perez J, Springthorpe VS, Sattar SA. Activity of selected oxidizing microbicides against the spores of Clostridium difficile: relevance to environmental control. Am J Infect Control 2005; 33:320-325.

42. Garner JS. Guideline for isolation precautions in hospitals. The Hospital Infection Control Practices Advisory Committee. Infect Control Hosp Epidemiol 1996; 17:53-80.

43. Siegel JD, Rhinehart E, Jackson M, Chiarello L, Healthcare Infection Control Practices Advisory Committee. 2007 Guideline for isolation precautions: preventing transmission of infectious agents in healthcare settings. June 2007. Available at: http://www.cdc.gov/ncidod/dhqp/pdf/isolation2007.pdf. Accessed December 13, 2007.

44. Lewis AM, Gammon J, Hosein I. The pros and cons of isolation and containment. J Hosp Infect 1999; 43:19-23.

45. Boyce JM, Ligi C, Kohan C, Dumigan D, Havill NL. Lack of association between the increased incidence of Clostridium difficile-associated disease and the increasing use of alcohol-based hand rubs. Infect Control Hosp Epidemiol 2006; 27:479-483.

46. Riggs MM, Sethi AK, Zabarsky TF, Eckstein EC, Jump RL, Donskey CJ. Asymptomatic carriers are a potential source of transmission of epidemic and nonepidemic Clostridium difficile strains among long-term care facility residents. Clin Infect Dis 2007; 45:992-998.

47. Wenisch C, Parschalk B, Hasenhündl M, Hirschl AM, Graninger W. Comparison of vancomycin, teicoplanin, metronidazole, and fusidic acid for the treatment of Clostridium difficile-associated diarrhea. Clin Infect Dis 1996; 22:813-818.

48. Surawicz CM, McFarland LV, Greenberg RN, et al. The search for a better treatment for recurrent Clostridium difficile disease: use of highdose vancomycin combined with Saccharomyces boulardii. Clin Infect Dis 2000; 31:1012-1017.

49. Wilcox MH, Fawley WN, Parnell P. Value of lysozyme agar incorporation and alkaline thioglycollate exposure for the environmental recovery of Clostridium difficile. J Hosp Infect 2000; 44:65-69.

50. Kaatz GW, Gitlin SD, Schaberg DR, et al. Acquisition of Clostridium difficile from the hospital environment. Am J Epidemiol 1988; 127:12891294.

51. Wilcox MH, Fawley WN, Wigglesworth N, et al. Comparison of the effect of detergent versus hypochlorite cleaning on environmental contamination and incidence of Clostridium difficile infection. J Hosp Infect 2003; 54:109-114.

52. Mayfield JL, Leet T, Miller J, Mundy LM. Environmental control to reduce transmission of Clostridium difficile. Clin Infect Dis 2000; 31:9951000.

53. McDonald LC. Confronting Clostridium difficile in inpatient healthcare facilities. Clin Infect Dis 2007; 45:1274-1276.

54. Valiquette L, Cossette B, Garant MP, Diab H, Pepin J. Impact of reduction in the use of high-risk antibiotics on the course of an epidemic of Clostridium difficile-associated disease caused by the hypervirulent NAP1/027 strain. Clin Infect Dis 2007; 45:S112-S121.

55. Pear SM, Williamson TH, Bettin KM, Gerding DN, Galgiani JN. Decrease in nosocomial Clostridium difficile-associated diarrhea by restricting clindamycin use. Ann Intern Med 1994; 120:272-277.

56. Johnson S, Homann SR, Bettin KM, et al. Treatment of asymptomatic Clostridium difficile carriers (fecal excretors) with vancomycin or metronidazole: a randomized, placebo-controlled trial. Ann Intern Med 1992; 117:297-302.

57. Siegel JD, Rhinehart E, Jackson M, Chiarello L, Healthcare Infection Control Practices Advisory Committee. Guideline for isolation precautions: preventing transmission of infectious agents in healthcare settings 2007. Available at: http://www.cdc.gov/ncidod/dhqp/pdf/guidelines/Isolation2007.pdf. Accessed January 15, 2008.

58. Wong ES, Rupp ME, Mermel L, et al. Public disclosure of healthcareassociated infections: the role of the Society for Healthcare Epidemiology of America. Infect Control Hosp Epidemiol 2005; 26:210-212.

59. McKibben L, Horan TC, Tokars JI, et al. Guidance on public reporting of healthcare-associated infections: recommendations of the Healthcare Infection Control Practices Advisory Committee. Infect Control Hosp Epidemiol 2005; 26:580-587.

60. Healthcare-Associated Infection Working Group of the Joint Public Policy Committee. Essentials of public reporting of healthcare-associated infections: a tool kit. January 2007. Available at: http://www.cdc.gov/ ncidod/dhqp/pdf/ar/06_107498_Essentials_Tool_Kit.pdf. Accessed April 6, 2007.

61. The National Quality Forum. National voluntary consensus standards, endorsed November 15, 2007. Available at: http://www.qualityforum.org/ pdf/news/lsCSACMeasures.pdf. Accessed December 20, 2007. 